\title{
Metal ions in Alzheimer's disease: A key role or not?
}

Yan Liu, ${ }^{\mathrm{a}^{*}}$ Michel Nguyen, ${ }^{\mathrm{b}}$ Anne Robert, ${ }^{\mathrm{b} *}$ Bernard Meunier ${ }^{\mathrm{a}, \mathrm{b}}$

${ }^{a}$ School of Chemical Engineering and Light Industry, Guangdong University of Technology (GDUT), Higher Education Mega Center, 100 Waihuan Xi road, Panyu District, Guangzhou, 510006, P. R. China.

${ }^{b}$ Laboratoire de Chimie de Coordination du CNRS (LCC-CNRS), 205 route de Narbonne, BP 44099, 31077 Toulouse cedex 4, France; and Université de Toulouse, 31077 Toulouse Cedex 4, France.

E-mail: yanliu@gdut.edu.cn, anne.robert@lcc-toulouse.fr

\section{Conspectus}

Despite tremendous research efforts in universities and pharmaceutical companies, effective drugs are still laking for the treatment of Alzheimer's disease (AD). The biochemical mechanisms of this devastating neurodegenerative disease have not yet been clearly understood. Beside a small percentage of cases with early-onset disease having a genetic origin $(<5 \%$, familial $A D)$, most patients develop in elderly a sporadic form due to the multiple and complex parameters of aging. Consequently, $\mathrm{AD}$ is spreading in all countries with a long life-expectancy.

$\mathrm{AD}$ is characterized by deposition of senile plaques made of $\beta$-amyloid proteins ( $\mathrm{A} \beta$ ) and by hyperphosphorylation of tau proteins, which have been considered as the main drug targets up to now. However, antibodies targeting amyloid aggregates, as well as enzyme inhibitors aiming to modify the amyloid precursor protein processing, have failed to improve cognition in clinical trials. Then, to set up effective drugs, it is urgent to enlarge the panel of drug targets.

Evidences of the link between $\mathrm{AD}$ and redox metal dysregulation have also been supported by post-mortem analyses of amyloid plaques, which contained accumulation of copper, iron, and zinc by 5.7, 2.8, and 3.1 times the levels observed in normal brains, 
respectively. Copper-amyloid complexes, in the presence of endogenous reductants, are able to catalyze the reduction of dioxygen and to produce reduced/reactive oxygen species (ROS), leading to neuron death. The possibility of using metal chelators to regenerate normal trafficking of metal ions has been considered as a promising strategy in order to reduce the redox stress lethal for neurons. However, the most attempts to use metal chelators as therapeutic agents have been limited to existing molecules available from the shelves. Very few chelators resulted from a rational design aiming to create drugs with a safety profile, and able to cross the blood-brain barrier after an oral administration.

In the human body, metals are handled by a sophisticated protein network to strictly control their transport and reactivity. Abnormal concentrations of certain metals may lead to pathological events due to mis-accumulation and non-regular reactivity. Consequently, therapeutic attempts to restore metal homeostasis should carefully take into account the coordination chemistry specificities of the concerned redox-active metal ions.

This review is focused on the role of the main biologically redox-active transition metals, iron and copper. For iron, the recent debate on the possible role of magnetite in AD pathogenesis is presented. The section devoted to copper is focused on the design of specific copper chelators as drug-candidates able to regulate the copper homeostasis and to reduce the oxidative damage responsible for the neuron death observed in AD brains. A short survey on non-redox-active metal ions is also included at the beginning, such as aluminum and its controversial role in $\mathrm{AD}$, and zinc which is a key metal ion in the brain.

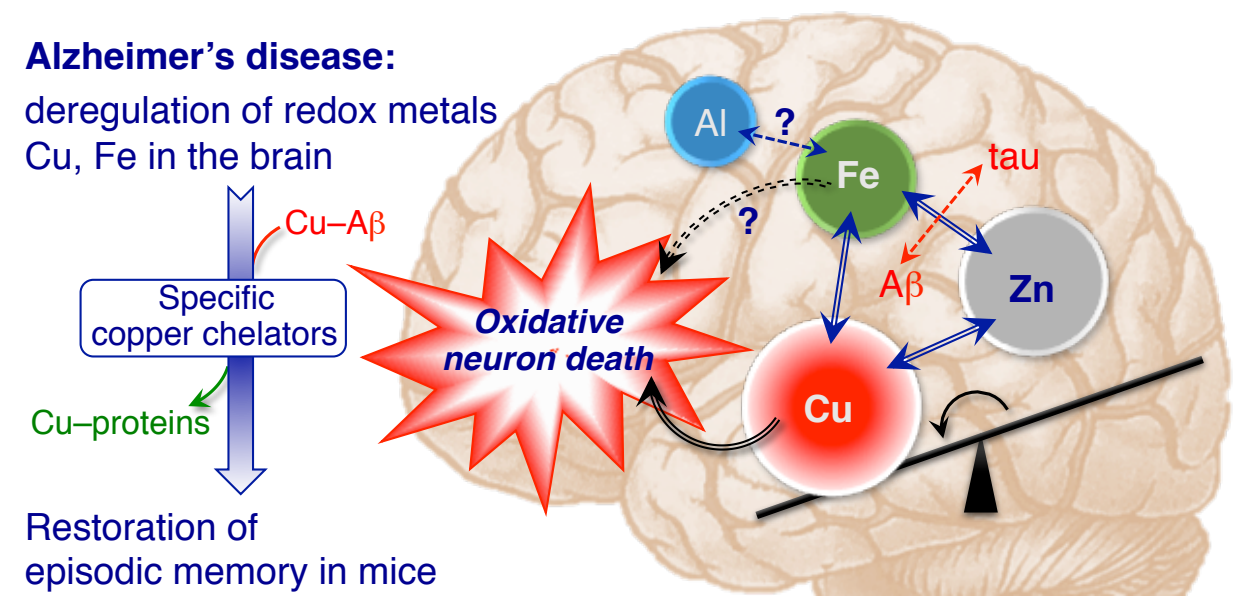

Scheme for the Conspectus 


\section{Introduction}

Currently, about 35 million of patients in the World are suffering from Alzheimer's disease (AD), a neurodegenerative condition related to aging. AD accounts for about $70 \%$ of cases of dementia, and this number is expected to reach 100 million in $2050 .{ }^{1}$ Since $95 \%$ of cases are sporadic without specific genetic cause, unlike the familial AD (or early-onset AD), this disease occurs in countries with long/increasing life-expectancy. ${ }^{2}$ The irreversible progressive cognitive dysfunction, impaired language skill, and personality changes, together with the duration of pathology, place considerable pressure on patients, families, caregivers, and on public health budgets. Current AD therapies based on few drugs (3 acetylcholine esterase inhibitors and memantine, antagonist of the $N$-methyl-D-aspartate receptor) have only a shortterm symptomatic effect, and their efficiency/cost ratios are questionable. ${ }^{3}$ The pipeline of new drugs is unproductive. Since approval of memantine in 2003, no new AD drug has been approved. Moreover, all clinical trials undertaken from 2002 to 2012, involving 244 new drug-candidates, except that of memantine, failed at different stages. ${ }^{3}$ So, it is urgent to escape from over-explored approaches, to use different targets and new animal models, to find new drugs able to stop or reduce the degenerative process in the early stage of the disease. ${ }^{4,5}$

The "amyloid cascade" hypothesis was the most investigated model of AD pathology. It proposed that the deposition of $\beta$-amyloid $(\mathrm{A} \beta)$ is the initial pathological event, leading to the formation of senile plaques, and then to neurofibrillary tangles (NFTs), neuronal cell death, and clinical dementia. While there is substantial evidence supporting the hypothesis, there are also limitations, and it is now called into question. ${ }^{6}$ However, antibodies targeting amyloid aggregates have failed to improve cognition. Accordingly, a priority is now to enlarge the panel of drug targets and therapeutic agents for this aging disease.

Besides this popular, yet ineffective, protein target, the evidences of the link between AD and redox metal dysregulation may lead to the possibility of an alternative solution. ${ }^{7}$ This approach is strongly supported by post-mortem analyses of amyloid plaques, which indicates an excessive accumulation of copper, iron, and zinc by 5.7, 2.8, and 3.1 times the levels 
observed in normal brains, respectively. ${ }^{8}$ Copper-amyloid complexes, in the presence of endogenous reductants, are expected to catalyze the reduction of dioxygen to generate reduced/reactive oxygen species (ROS) involved in neuron death. ${ }^{9,10}$ Therefore, it is a promising way to reduce redox stress by using metal chelators, to regenerate normal trafficking of metal ions. ${ }^{11-13}$

Therapeutic attempts to restore metal homeostasis should take into account the coordination chemistry specificities of the concerned metals. The present review is focused on the role of the main redox-active transition metals, iron and copper. For iron, the recent debate on the possible role of magnetite in $\mathrm{AD}$ pathogenesis is presented. The section on copper is focused on the design of specific copper chelators as drug-candidates able to regulate the copper homeostasis and to reduce AD oxidative damage in the brain. In addition, we included a short survey on non-redox-active metal ions, such as aluminum and its controversial role in $\mathrm{AD}$, and zinc, a key ion in the brain.

\section{Is Aluminum involved in Alzheimer's disease?}

The source of aluminum in humans is essentially oral intake from food, drinking water, and Al-containing drugs. Normally, the digestive tract is an effective barrier, resulting in a very low gastrointestinal absorption of aluminum $(<0.1 \%$ of ingested dose $) .{ }^{14}$

The possible role of aluminum in the etiology of AD started in 1965 with the accidental discovery that injections of aluminum salts in the brain of rabbits induced "neuronal changes [...that] consisted primarily in a neurofibrillary degeneration". ${ }^{15}$ These Al-induced neurofibrillary tangles (NFTs) were considered reminiscent of AD pathogenesis, along with a questionable elevated concentration of $\mathrm{Al}$ in the brains of patients with $\mathrm{AD},{ }^{16}$, and a controversial correlation between dementia and $\mathrm{Al}$ concentration in drinking water. ${ }^{17}$ Aluminum-induced tangles of rabbits are morphologically distinct from those of AD patients, and the difference in $\mathrm{Al}$ concentration between normal brains and patients with dementia was disclaimed. ${ }^{18}$ In 1998, in a key review article, Munoz summarized different arguments leading to the conclusion that there is no direct role of aluminum ions in AD. ${ }^{19}$ 
During the same period, aluminum intoxication has been reported in patients with chronic renal failure (CRF), either under hemodialysis $(\mathrm{HD})^{20}$ or not. ${ }^{21}$ The different neurological syndromes associated with Al-overload have therefore been extensively studied in CRF patients. $^{22}$ The dialysis encephalopathy syndrome (DES, or dialysis dementia) was characterized by speech disturbances, myoclonus and epileptic seizures, with clinical signs different from the $\mathrm{AD}$ ones. ${ }^{20}$ The intoxication was due to Al-containing tap-water used for dialysis fluids in the 1960s-1970s. Quickly after, dialysis fluids were deionized, and this dialysis dementia disappeared. ${ }^{23}$ In addition, a dialysis-associated encephalopathy (DAE) has been observed, resulting of a "long-term low-dose aluminum intake" of oral aluminum drugs administrated to control the hyperphosphatemia of patients. Neuronal changes were exclusively observed in long-term HD patients. ${ }^{23}$ To eliminate this aluminum toxicity, Al-free phosphate binders have been developed, and the use of $\mathrm{Al}$ derivatives is now restricted to short-term treatments. ${ }^{24}$ In fact, DAE long-term hemodialyzed patients did not present any statistical increase of brain AD-morphology, in comparison to age-matched controls. ${ }^{23} \mathrm{Few}$ publications continue to claim that aluminum is involved in AD neuropathology without convincing evidences. ${ }^{25,26}$ All in all, there is no new data allowing to modify the Munoz's statement published 30 years ago on the absence of aluminum role in AD. ${ }^{19,27}$

Since $\mathrm{Al}(\mathrm{III})$ and $\mathrm{Fe}(\mathrm{III})$ have similar ionic radii [0.675 $\AA$ for $\mathrm{Al}(\mathrm{III}), 0.690$ and $0.785 \AA$ for low spin and high spin $\mathrm{Fe}(\mathrm{III})$, respectively], $\mathrm{Al}(\mathrm{III})$ can bind to ferritin, and compete with iron for its binding to the transporter transferrin (Tf). ${ }^{28}$ Consequently, the Tf receptor may deliver Al-loaded $\mathrm{Tf}$ to the brain. ${ }^{29}$ Since aluminum-overloading might disturb the iron homeostasis, WHO recommends to keep aluminum concentration in drinking water below 0.1 $\mathrm{mg} / \mathrm{L}{ }^{30}$

\section{Zinc : a non-redox active metal ion essential for brain function}

The stable divalent cation $\mathrm{Zn}^{2+}$ is essential for life, and is the second most abundant d-block metal after iron in the human body. It participates in numerous and diverse biological processes, including cell division, DNA and protein synthesis, wound healing, immunity, and 
cognition. $^{31,32}$ It has been proposed that 2,800 human proteins are potentially zinc-binding ones in vivo, corresponding to $10 \%$ of the human proteome. ${ }^{31}$ Zinc concentration in the brain is estimated to $150 \mu \mathrm{M}, 10$ times higher than in serum. ${ }^{32} \mathrm{Zn}^{2+}$ plays a dynamic role in both the physiology and the physiopathology of brain function. ${ }^{33,34}$ In the central nervous system, metallothionein-3 (MT-3) is one of the major players in the homeostasis of zinc, which is chelated as metal-thiolate clusters. ${ }^{35}$ This protein was found down-regulated in AD. ${ }^{35}$ The $\mathrm{Zn}(\mathrm{II})$-dependent metalloproteinases produce the brain-derived neurotrophic factor (BDNF), an important regulator of differentiation and survival of neuronal cells, that is also downregulated in $\mathrm{AD} .^{6}$

Most of the zinc (80-90\%) is tightly bound in metal protein-complexes to achieve enzymatic activity or structural stability. $10-15 \%$ of the brain zinc is present in a loosely bound or "mobile" form (mZn), mainly in the forebrain, cortex, amygdala, and especially hippocampus, an area associated to memory and learning. ${ }^{36}$ Zinc ion is a potent allosteric inhibitor of NMDA receptors. ${ }^{37}$ The high concentration of $\mathrm{mZn}(>100 \mu \mathrm{M})$ within glutamatergic vesicles, associated with the importance of glutamate as a neurotransmitter, led to the hypothesis that $\mathrm{mZn}$ may act as a neuromodulator. ${ }^{38}$

On the other hand, $\mathrm{Zn}^{2+}$ promotes both neuronal and glial death in vitro and in vivo by affecting multiple pathways, and is involved in various pathological conditions associated with excitotoxicity, including ischemia, epilepsy, brain trauma, and neurodegenerative diseases including AD. ${ }^{34}$ At the cellular level, $\mathrm{mZn}$ is loaded into presynaptic vesicles by the zinc transport protein ZnT3 that thus plays a role in modulating neurotransmission and plasticity of glutamatergic neurons. In mouse models, genetic deletion of ZnT3 resulted in a reduced synaptic localization of amyloid- $\beta$ oligomerization compared to wild-type mice, ${ }^{39}$ in an accelerated age-dependent loss in cognitive ability and in an impairment of the forms of memory that depend on hippocampal function, such as spatial working memory and contextual discrimination. ${ }^{38}$

In the context of $\mathrm{AD}$, the concentration of zinc in senile plaques (SP) and neuropils of $\mathrm{AD}$ patients was reported to be increased by a factor of 3- and 2.3-fold, respectively, with respect to the concentration of zinc in control neuropils. ${ }^{8}$ In controversial articles, authors 
reported an increase,${ }^{40}$ or a decrease,${ }^{16}$ of zinc concentration in AD hippocampus or amygdala with respect to controls.

Despite ZnT3 protein levels are decreased in AD post-mortem brain tissue, an increase in presynaptic $\mathrm{mZn}$ has been proposed to be involved in pathogenesis, by promoting oligomerization and aggregation of amyloid- $\beta$, a process resulting in accumulation of insoluble Zn-rich senile plaques. ${ }^{32}$ In fact, zinc binds to amyloids with affinities in the low micromolar range..$^{41}$

Zinc has also been reported to modulate the activity of secretases that cleave the amyloid precursor protein (APP) to generate $A \beta,{ }^{32}$ and to induce a dose-dependent increase in $A \beta$ resistance to the A $\beta$-degrading protease matrix metalloprotease-2, MMP2. ${ }^{42}$ Zinc has also been considered able to contribute to tauopathy by promoting the direct toxicity of tau protein, ${ }^{43}$ or the hyperphosphorylation of the tau protein by inhibition of protein phosphatase $2 \mathrm{~A} .{ }^{44}$

To eliminate the excess of intracellular $\mathrm{Zn}^{2+}$, tpen was proposed as chelator [tpen $=$ $N, N, N, N$-tetrakis(2-pyridylmethyl)ethylenediamine, $\log K_{\text {aff }}(\mathrm{Zn}$-tpen) $=15.2] \cdot{ }^{33,38}$ However tpen is rather toxic and has a much higher affinity for $\mathrm{Cu}(\mathrm{II})$ than for $\mathrm{Zn}(\mathrm{II}),\left[\log K_{\text {aff }}\left(\mathrm{Cu}^{\mathrm{II}}-\right.\right.$ tpen) $=19.8],{ }^{38}$ Therefore this ligand is likely to interfere with the homeostasis of redoxactive metal ions. Moreover, $\mathrm{Zn}^{2+}$ deprivation can also trigger neuronal death, so that early dietary $\mathrm{Zn}$ supplementation of an $\mathrm{AD}$ mouse model was reported to prevent hippocampaldependent cognitive deficits. ${ }^{34}$

Noteworthy, zinc competes with copper for amyloid coordination, ${ }^{45}$ and supplementation has been reported to influence copper distribution in the brain. On the other hand, APP is essential for ferroportin persistence on the neuronal surface. ${ }^{46}$ Since $\mathrm{Zn}^{2+}$ is a substrate of ferroportin, it may indirectly take part in iron trafficking. These works illustrate the subtle role of zinc, a non-redox active metal, including in the regulation and the activity of redox metals such as copper and iron, in the brain. For this additional reason, metal chelators, if considered as drug-candidates, should obviously be specific for a particular metal.

\section{What do we know about brain damage and iron ions?}


The adult human body contains 3.5-4.0 grams of iron. Each day, 1 to $2 \mathrm{mg}$ of iron enters or leaves the human body. Fetal and neonatal lifes are periods of fast growth of brain. Iron deficiency in these periods limits the proliferation and differentiation of brain tissues with decrease of learning ability and memory. In fact, iron is the most abundant $d$-metal ion in human brain, with reported concentration as high as $40 \mathrm{mg} / \mathrm{g}$ (ca. $720 \mu \mathrm{M}$ ) in the total brain of healthy adults. ${ }^{47}$ Iron-enzymes are involved in neurotransmitter synthesis (e.g. production of L-dopa from tyrosine by tyrosine hydroxylase) and in myelination of neurons. Alteration of iron metabolism, with accumulation in the striatum, is considered as a molecular signature of aging, linked to poorer memory. ${ }^{48}$ In healthy conditions, the inter-conversion of the two main oxidation states of iron, $\mathrm{Fe}(\mathrm{III}) / \mathrm{Fe}(\mathrm{II})$, is strictly controlled to avoid the catalytic reduction of dioxygen by $\mathrm{Fe}(\mathrm{II})$, that should result in the formation of damaging ROS. The distinction between normal and pathological aging is necessary to develop therapeutic tools.

Disruption of iron trafficking, with significant local accumulation in the brain and altered storage, has been suspected in several neurodegenerative diseases, including AD, since the early $1950 \mathrm{~s} .{ }^{49}$ Its concentration in a large number of AD brain regions is higher than that in normal brains, with accumulation in senile plaques and neurofibrillary tangles, enhancing them as redox active sites. ${ }^{8,50}$ Iron regulation is also related to proteins involved in $\mathrm{AD}$, as emphasized above for the ferroportin regulation by APP. ${ }^{46}$ Iron accumulation also leads to microglia activation, resulting in neuro-inflammation and neuro-degeneration, via ROS production.

In $\mathrm{AD}$ brain, despite the accumulation of iron in amyloid plaques was reported, the link between iron and ROS production remains to be clearly established. The coordination of $\mathrm{Fe}(\mathrm{II})$ to amyloids under strictly anaerobic conditions, ${ }^{51}$ and that of $\mathrm{Fe}(\mathrm{III})$ have been reported. ${ }^{52}$ But the production of ROS by iron-amyloids in vitro is much less efficient than that of copper-amyloids. ${ }^{53}$ In addition, the competitive hydrolysis of free iron salts to insoluble and consequently poorly reactive $\mathrm{Fe}(\mathrm{OH})_{3}$ is expected to be favored and the formation of a redox-active binary $\mathrm{Fe}(\mathrm{III} / \mathrm{II})-\mathrm{A} \beta$ complex is unlikely at physiological $\mathrm{pH}$. 
Among the possible iron sources involved in brain damage, magnetite, a mixed valence $\mathrm{Fe}(\mathrm{II}) \mathrm{O} \cdot \mathrm{Fe}(\mathrm{III})_{2} \mathrm{O}_{3}$ iron oxide has been evoked. Biogenic magnetite has been detected in human brain twenty-five years ago. ${ }^{54}$ Based on the putative peroxidase activity of this highly insoluble iron ore, ${ }^{55}$ studies have pointed to the putative role of magnetite to trigger neurodegenerative diseases by coordination to amyloid peptides, thus linking AD and magnetite. ${ }^{56}$ Recently, brain magnetite was considered to be non-endogenic, but coming from an external source, namely combustion-derived particulate matters and/or nanoparticles, thus suggesting a direct link between urban pollution and AD. ${ }^{57}$ We recently invalidated this hypothesis by showing that magnetite is not catalytically competent to oxidize standard peroxidase substrates in vitro, especially at biological $\mathrm{pH}$ value of $7.4{ }^{58}$ The fluorescence produced by oxidation of a peroxidase substrate in the presence of magnetite nanoparticles was below that produced in a non Chelex-treated buffer, in the absence of any extra iron species (Figure 1, black traces), suggesting that the very low oxidation reported in the presence of magnetite is likely due to adventitious metal impurities. Under similar conditions, very low concentrations of a true peroxidase such as horseradish peroxidase (HRP) exhibit a real dose-dependent catalytic activity (Figure 1, blue traces). In addition, magnetite does not significantly interact with $\mathrm{A} \beta$ in vitro, and magnetite and iron oxides/hydroxides were found unable to induce, either in the presence or in the absence of $A \beta$, the reductive activation of dioxygen, which is the first step of an oxidative stress. Even if the long scale time of development of neurodegenerative diseases is not taken into account in these in vitro experiments, these results strongly suggest that magnetite or iron oxides/hydroxides are probably not directly involved in Alzheimer's disease brain damages. ${ }^{58}$ 


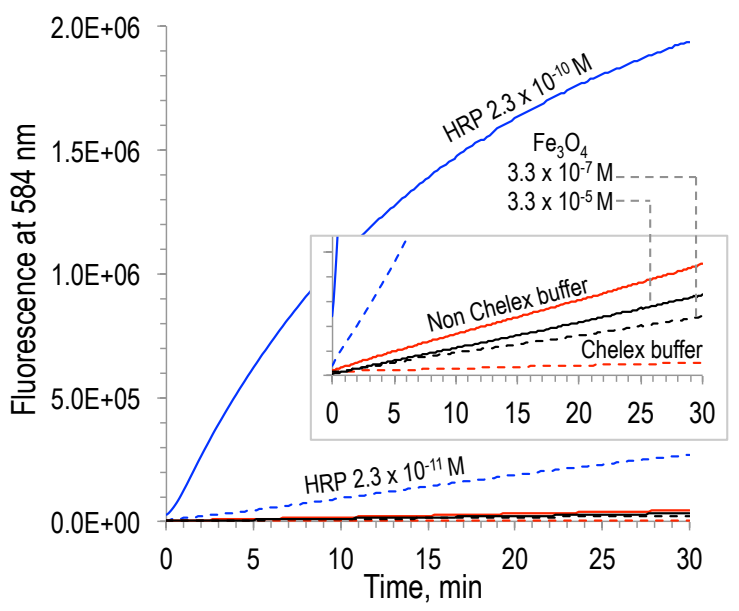

Figure 1. Peroxidase activity measured by the fluorescence of the reaction product in the Red hydrogen peroxide assay kit, in the presence of $\mathrm{H}_{2} \mathrm{O}_{2} 1 \mathrm{mM}, \mathrm{pH} 7.4,37^{\circ} \mathrm{C}$, using HRP $2.3 \times 10^{-10} \mathrm{M}$ or $2.3 \times 10^{-11} \mathrm{M}$ (full- and dashed blue traces, respectively), or $\mathrm{Fe}_{3} \mathrm{O}_{4} 3.3 \times 10^{-7} \mathrm{M}$ or $3.3 \times 10^{-5} \mathrm{M}$ (full- and dashed black traces, respectively). Fluorescence in the presence of $\mathrm{H}_{2} \mathrm{O}_{2}$ alone $(1 \mathrm{mM})$ in Chelex treated(dashed red trace) or non treated buffer (full red trace) is given for comparison.

In this case, what other iron species may be responsible for oxidative stress in AD brain? There is a growing body of evidence suggesting that the neurovascular coupling, defined as the link between transient neural activity and the corresponding increase of cerebral blood flow, may be impaired in $\mathrm{AD}$, leading to stroke. ${ }^{59}$ Vascular pathology, including small hemorrhages, is very common in the brain of AD patients, suggesting that breakdown of the microvasculature, and release of the pro-oxidant heme, may be a major event of $\mathrm{AD}^{60}$ In vitro, the iron center of hemin was reported to bind $A \beta$, modulate its aggregation, ${ }^{61}$ and the hemin-A $\beta$ complex has an enhanced peroxidase activity relative to free hemin. ${ }^{62}$ In case of bleeding and accumulation of toxic heme in the brain, the up-regulation of the hemeoxygenase-1 (HO)/biliverdine reductase is the adaptive response to stress. ${ }^{63}$ If heme release is not associated with an adequate iron recycling, specially an increase in transferrin and ferritin expression, HO-induced oxidative cleavage of heme is expected to generate low molecular weight complexes between iron and heme fragments, having significant redox activity, thus exacerbating brain injury. ${ }^{64}$

Recent epidemiological data suggested that, in the western World, dementia is currently decreasing as a result of better vascular care. ${ }^{65}$ In conclusion, the vascular status of the brain 
and the efficiency of iron recycling metabolism may be relevant to reduce AD cases. The molecular bases of this hypothesis remain to be experimentally documented.

\section{Copper chelators as anti-AD drug-candidates targeting Copper-amyloids}

The copper concentration in human frontal lobe and cerebellum is in the range of 60-110 $\mu \mathrm{M} .{ }^{66}$ Copper ions are essential co-factors for several essential metallo-enzymes. For example, tyrosinase produces L-dopa from tyrosine, and catecholamine neurotransmitters. ${ }^{67}$ Circadian rhythm dysfunction occurs in $\mathrm{AD}$, and copper was recently reported to modulate rest-activity cycles via norepinephrine produced by the copper enzyme dopamine $\beta$ hydroxylase. ${ }^{68}$

If not structurally bound and chemically regulated by physiological copper proteins, and in the presence of endogenous reductants, the redox cycle of $\mathrm{Cu}(\mathrm{II}) / \mathrm{Cu}(\mathrm{I})$ generates hydroxyl radicals $\mathrm{HO}^{\bullet}$ responsible for oxidative damage involved in aging and neuron death. ${ }^{9}$ Complexes of copper of $\beta$-amyloids short oligomers, able to penetrate neurons, might trigger this oxidative stress within different neuronal sub-compartments. ${ }^{10}$ Such a catalytic process causes overconsumption of endogenous antioxidants, and their depletion in neurons. Moreover, the sequestration of copper in amyloid plaques may generate a deficit in other compartments of the brain and reduce the $\mathrm{Cu}, \mathrm{Zn}-\mathrm{SOD}$ activity. ${ }^{69}$ So, the disruption of copper homeostasis and its accumulation to $\beta$-amyloids contributes to the redox stress that decreases the neuron population in $\mathrm{AD}$ brain. ${ }^{12,70}$

The restoration of copper homeostasis by using specific chelators has been considered a key pharmacological target. ${ }^{11,12}$ The challenge is to design ligands (i) able to cross the bloodbrain barrier, (ii) specific for copper chelation and (iii) innocent with respect to copperenzymes or other metallo-proteins. These chelators should be able to extracted copper from $\mathrm{Cu}$-amyloids complexes, and then release copper in favor of copper-carrier proteins, without causing copper depletion within the brain. Such drugs should be able to inhibit the ROS production induced by $\mathrm{Cu}$-amyloids in the presence of endogeneous reductants. 
Clioquinol (CQ) and PBT2, two 8-hydroxyquinolines derivatives, were considered as prototypes of copper chelators for $\mathrm{AD}$ therapy (Figure 2). ${ }^{71}$ Unfortunately, clioquinol, formerly used as antifungal and antiprotozoal, has been withdrawn from the market in 1983, due to its neurotoxicity attributed to zinc chelation. ${ }^{72}$ This feature pointed out the need to design chelators with high specificity for copper. Both CQ and PBT2 entered anti-AD clinical trials, but failed due to their lack of efficacy. ${ }^{73}$ CQ and PBT2 are bi- and tridentate ligands, respectively, while a stable coordination of $\mathrm{Cu}$ (II) requires (at least) 4 coordinating functions. The $\mathrm{Cu}(\mathrm{II})$ complexes of $\mathrm{CQ}$ and PBT2 have a 1/2 metal/ligand stoichiometry. ${ }^{12,74}$ Consequently, in the presence of $\mathrm{Cu}^{\mathrm{II}}-\mathrm{A} \beta$ in vitro, stoichiometric amounts of $\mathrm{CQ}$ or PBT2 generate stable ternary complexes with $\mathrm{Cu} \mathrm{u}^{\mathrm{II}}-\mathrm{A} \beta .^{74,75} \mathrm{In}$ addition, PBT2 is a good zinc chelator able to make complexes with different structures within the same crystal. ${ }^{75}$ Then, the coordination chemistry of 8-hydroxyquinolines is not suitable to extract copper(II) bound to amyloids, and these bidentate ligands are not effective mediators between $\mathrm{Cu}-\mathrm{A} \beta$ and $\mathrm{Cu}$ carrier-proteins for the regulation of copper ions in $\mathrm{AD}$ brains. ${ }^{75}$

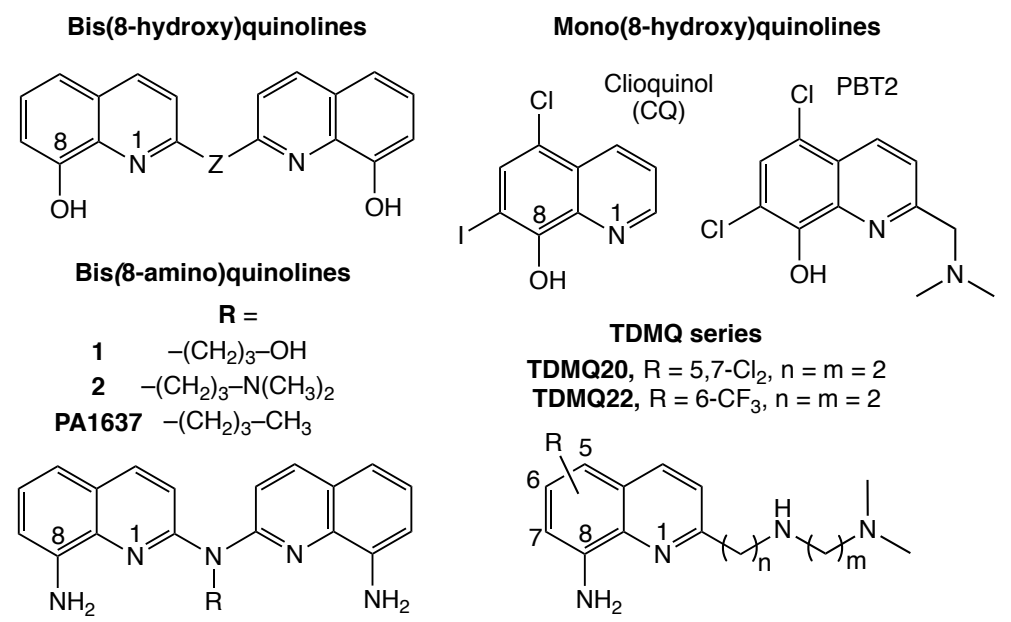

Figure 2. Structures of 8-aminoquinolines and 8-hydroxyquinolines copper chelators. Z stands for different types of linkers (alkyl, amine, ester...).

In contrast to mono(8-hydroxy)quinolines, bis(8-hydroxy)quinolines (Figure 2) offer four binding sites (a N2O2 tetradentate motif) within a single molecule, giving rise to complexes with metal/ligand stoichiometry $=1 / 1 .^{76}$ The affinity for copper(II) of such tetradentate ligands is higher by 4-6 orders of magnitude than that of mono(8-hydroxy)quinolines, and 
their selectivity for copper with respect to zinc is 100 to 1000 . However, their affinity for $\mathrm{Zn}(\mathrm{II})$ is still significant, making poor discrimination between copper and zinc.

To enhance the chelating selectivity of chelators, we designed a series of N4-tetradentate quinolines based on the bis(8-amino)quinoline scaffold. These bis(8-amino)quinolines, designed to be able to cross the blood-brain barrier, are specific for the chelation of copper (1, 2, and PA1637, Figure 2). ${ }^{11,77,78}$ These ligands L have a very high affinity for $\mathrm{Cu}(\mathrm{II})$, with $\log$ $K_{\text {app }}$ in the range $14-16$ at $\mathrm{pH} 7.4$, and their selectivity for $\mathrm{Cu}(\mathrm{II})$ with respect to $\mathrm{Zn}$ (II) is very high, with $\log \left[K_{\text {app }} \mathrm{Cu}-\mathrm{L} / K_{\text {app }} \mathrm{Zn}-\mathrm{L}\right]>12 .{ }^{77}$ In vitro, at low concentrations, these chelators efficiently and readily extract copper from $\mathrm{Cu}(\mathrm{II})-\mathrm{A} \beta$, to produce the corresponding $\mathrm{Cu}(\mathrm{II})-\mathrm{L}$ complexes. ${ }^{74}$ This series of drugs offers a square planar coordination that is suitable for $\mathrm{Cu}(\mathrm{II})$ but not for $\mathrm{Cu}(\mathrm{I})$. So, in the presence of glutathione $(\mathrm{GSH})$, playing the role of both reducing agent and competitive ligand for copper, the $\mathrm{Cu}(\mathrm{II})-\mathrm{L}$ complex quickly releases copper to generate a copper-glutathione complex that is capable of transferring copper to an apo-copper protein. ${ }^{78}$ In such process, the bis(8-amino)quinoline ligand $\mathrm{L}$ is released and can be re-used to extract again copper from $\mathrm{Cu}(\mathrm{II})-\mathrm{A} \beta$, operating in a catalytic fashion (Figure 3). Such virtuous mechanism is essential for a drug called to act as a copper regulator. A non-catalytic process should require a higher concentration of ligand, i.e. a higher dose of drug.

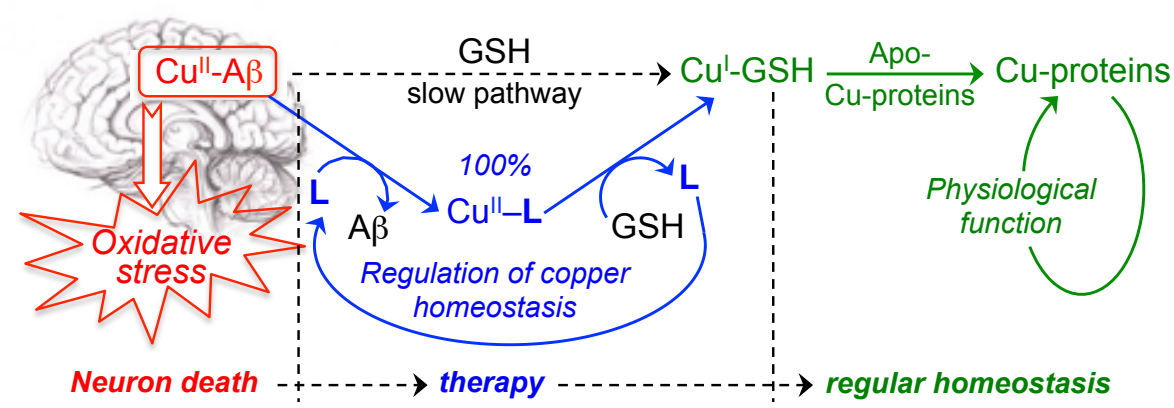

Figure 3. Transfer of copper ions from $\mathrm{Cu}-\mathrm{A} \beta$ to $\mathrm{Cu}$-proteins, using bis(8-amino)quinolines as mediating chelators.

However, in order to enhance the solubility and druggability of copper chelators, we designed a new series of N4-tetradentate copper ligands named TDMQ, based on a mono(8amino)quinoline with a lateral chain containing two additional binding sites (Figure 2). ${ }^{79,80}$ The $\log \mathrm{P}$ values of TDMQ chelators are in the range 2.5-3.5, expected for crossing the BBB. ${ }^{81}$ 
Several of these ligands are specific for copper compared to zinc, and able to induce the two discrete steps required to recycle copper into a normal physiological circulation, namely the extraction of copper from $\mathrm{Cu}-\mathrm{A} \beta$, followed by the release of copper from $\mathrm{Cu}$-TDMQ complexes in the presence of glutathione. This copper transfer is fully effective even in the presence of an excess of $\mathrm{Zn}(\mathrm{II})$ ions, mimicking the zinc-rich environment of the brain. ${ }^{82}$ TDMQ20 or TDMQ22 can be considered as lead molecules. As the above mentioned bis(8amino)quinoline 1, TDMQ20 (Figure 1) have a high selectivity for $\mathrm{Cu}(\mathrm{II})$ with respect to $\mathrm{Zn}(\mathrm{II})\left\{\log \left[K_{\text {app }} \mathrm{Cu}-\mathrm{L} / K_{\text {app }} \mathrm{Zn}-\mathrm{L}\right]>12\right\}$, much higher than that of $\mathrm{A} \beta\left\{\log \left[K_{\text {app }} \mathrm{Cu}-\mathrm{A} \beta /\right.\right.$ $\left.\left.K_{\text {app }} \mathrm{Zn}-\mathrm{A} \beta\right]=4-5\right\}$, and thus fulfill the criteria for pertinent copper regulators. ${ }^{82}$

Both TDMQ20 and 1 specifically chelate $\mathrm{Cu}(\mathrm{II})$ in a nearly perfect N4-square planar fashion (Figure 4), with a poor capacity to fit with the preferred tetrahedral coordination requested for $\mathrm{Cu}(\mathrm{I}) \cdot{ }^{77,79,80}$

(a) Cull-TDMQ20
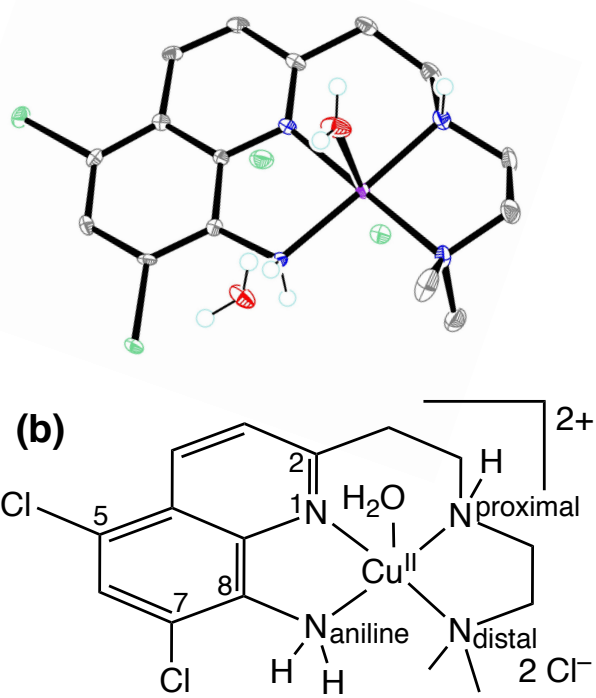

Figure 4. X-ray structure (a) and scheme (b) of the N4- square planar $\mathrm{Cu}(\mathrm{II})$ complex of TDMQ20.83

This structural feature is essential to make efficient inhibitors of the ROS production induced by $\mathrm{Cu}-\mathrm{A} \beta$. In vitro, TDMQ20 and $\mathbf{1}$ are able to immediately and completely stop the ongoing aerobic oxidation of ascorbate induced by $\mathrm{Cu}-\mathrm{A} \beta_{1-16}$, even in the presence of 100 mol equiv of $\mathrm{Zn}$ (II) with respect to copper (Figure 5), while a reduced Schiff base ligand with 
a N2O2-coordination sphere, or PBT2 (whose copper complex has a metal/ligand stoichiometry $=1 / 2$, and a $\mathrm{N} 3 \mathrm{O} 2$-coordination sphere) failed to inhibit the dioxygen reduction either in the presence or in the absence of zinc. ${ }^{82}$ In addition, TDMQ chelators (up to millimolar concentrations) do not affect in vitro the catalytic activities of $\mathrm{Cu}, \mathrm{Zn}$-superoxide dismutase and tyrosinase, two copper enzymes expressed in the brain and involved in the regulation of redox processes. ${ }^{84}$ The preliminary data on in vitro metabolism by microsomes and caco-2 underlines the druggability of the TDMQ ligands (unpublished data).

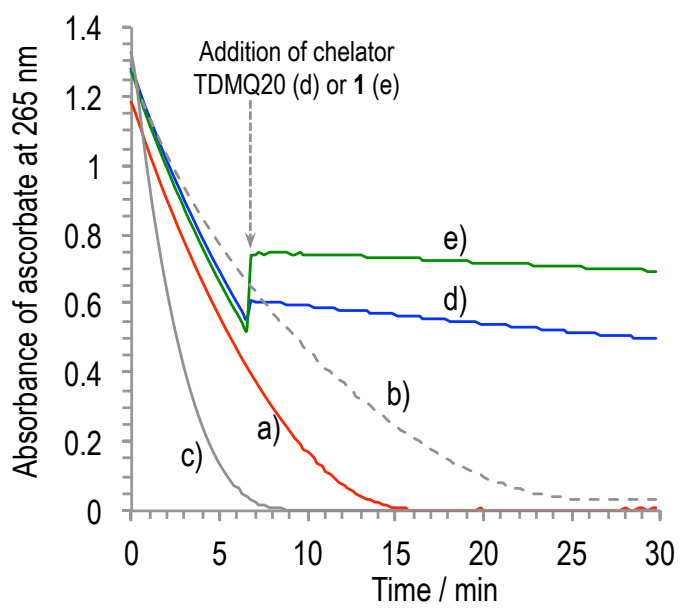

Figure 5. UV-visible $(265 \mathrm{~nm})$ kinetic spectra of ascorbate oxidation under air, in the presence of $\mathrm{CuCl}_{2} / \mathrm{A} \beta_{1-16} / \mathrm{ZnCl}_{2}=1 / 1 / 100$, then addition of $\mathrm{L}(1 \mathrm{~mol}$ equiv) at $6.6 \mathrm{~min}$ (arrow): $L=$ no ligand (trace a), $L=T D M Q 20$ (trace $d$ ), $L=1$ (trace e). The ascorbate oxidation in the presence of $\mathrm{CuCl}_{2} / \mathrm{A} \beta_{1-16}$, (trace $\mathrm{b}$ ), or $\mathrm{CuCl}_{2}$ alone (trace $\mathrm{c}$ ) are given for comparison. The increase of absorbance upon addition of TDMQ20 (d) or 1 (e) at $6.6 \mathrm{~min}$, is due to the own absorbance of Cull-TDMQ20, or Cull-1 at $265 \mathrm{~nm}$.

To evaluate the ability of copper chelators to reduce the loss of memory in vivo, after being disappointed by previous experiences with transgenic models, ${ }^{85}$ we elaborated a nontransgenic mouse model. As indicated above, all failed clinical trials were carried out after selection of drugs using similar transgenic mice. Diversification of animal models should be considered as a crucial point to go further on AD pharmacology. Moreover, transgenic mice mimik the late stage of the disease, which is poorly relevant to desired actions in AD. Consequently, we used regular mice in which a deficit of episodic memory mimicking the early stages of $\mathrm{AD}$ cognitive impairment was created by a single intracerebroventricular (icv) 
injection of $\mathrm{A} \beta_{1-42}$ oligomers ("icv-AD" model). ${ }^{86}$ No loss of memory was observed when the reverse peptide $A \beta_{42-1}$ was injected, thus indicating the robustness of the model.

One of the bis(8-amino)quinoline chelators, PA1637 (Figure 2), was found efficient to inhibit the memory deficit induced by icv injection of $A \beta_{1-42}$ oligomers. ${ }^{86}$ After oral treatment with 8 doses of PA1637 (25 mg/kg/doses, over a 3-week period), the episodic memory of icv-AD mice (Figure 6, gray bar) was similar to that of healthy animals (white bar), while the episodic memory of $\mathrm{AD}$ mice that did not receive treatment was significantly reduced (black bars). Treatment with PA1637 at the lower dose of $12.5 \mathrm{mg} / \mathrm{kg}$ provided the same result (data not shown). These results indicate that oral administration of PA1637 fully inhibited the cognitive impairment induced by icv injection of $A \beta$-oligomers. ${ }^{86}$

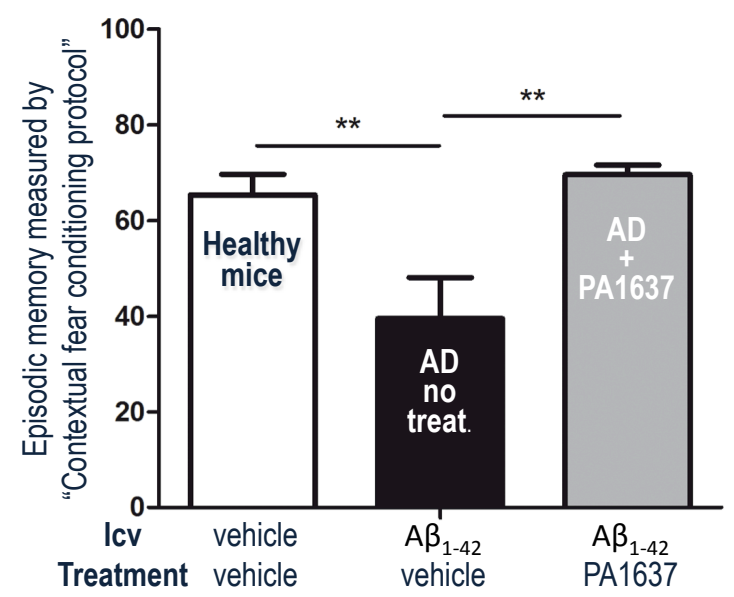

Figure 6. Episodic memory of non-transgenic $A D$ mice treated with PA1637 at $25 \mathrm{mg} / \mathrm{kg}$ by oral route (grey bar), compared to healthy control mice and untreated AD mice. For details, see Ref. 86.

In summary, the design of chelators as drug candidates for copper regulation in AD brain should obey to some critical coordination requirements. Among the various possibilities offered by the diversity of metal ligands, we found that N4-tetradentate 8-aminoquinoline ligands are suitable to transfer copper from metal-amyloids to metal-carrier proteins, and are capable of inhibiting the catalytic reduction of dioxygen produced by copper-loaded amyloids exposed to a reductant. In vivo, such tetradentate ligands are able to inhibit the loss of episodic memory in non-transgenic amyloid-impaired mice. These results strongly support the 
targeting of copper homeostasis for AD chemotherapy. Pharmacological studies on the more water-soluble TDMQ molecules that exhibit the suitable coordination sphere for copper specificity are currently in progress.

\section{Conclusion}

Besides protein targets, regulation of the most abundant biological d-block metals, namely iron, copper, and zinc, is increasingly considered a valuable target for Alzheimer's disease therapy. Distribution of these three metals is linked together, and also connected to amyloid and tau metabolism. For instance, APP is essential for the activity of ferroportin which is an iron-efflux protein able to also transport zinc. Zinc and copper regulate $\mathrm{A} \beta$ production by distinct mechanisms affecting the processing of APP. In addition, modulation of tau phosphorylation and APP processing are linked to the zinc-induced activation of synaptic NMDA receptors. A part of the metal-dependent metabolic processes involved in AD is depicted in Figure 7. While it is not the single one, regulation of copper homeostasis may be a kind of hub target.

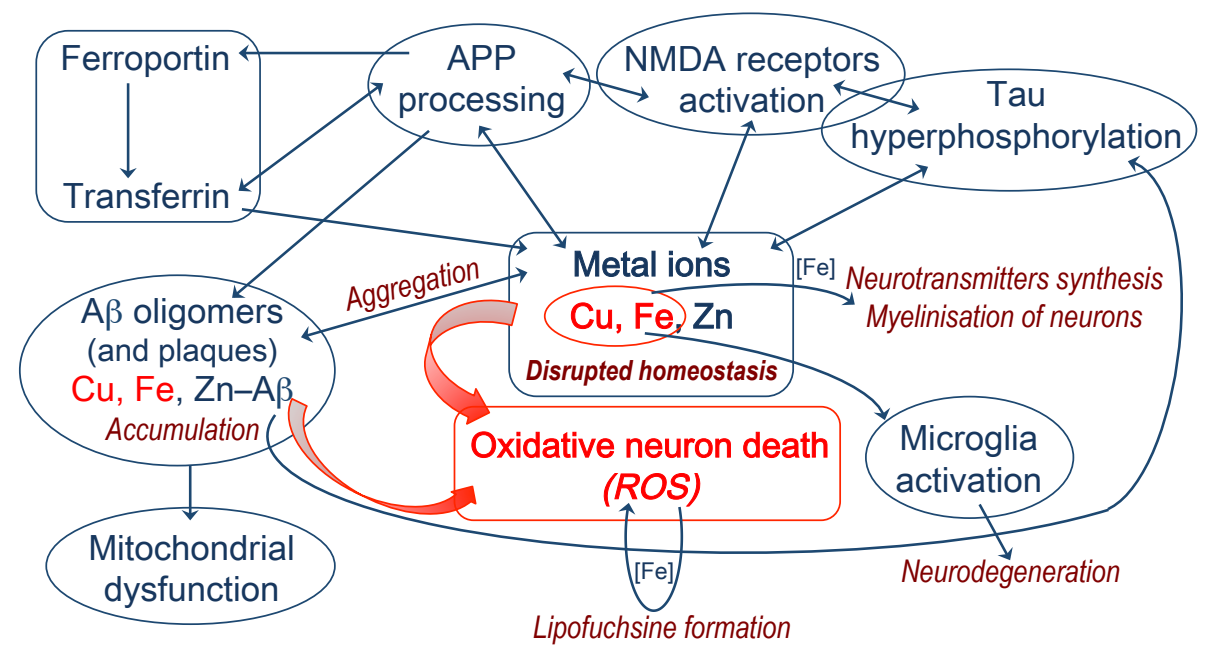

Figure 7. Schematic description of some of the metal-dependent metabolic pathways involved in $A D$ pathogenesis.

The development of metal regulators as drugs to restore copper homeostasis in $\mathrm{AD}$ brains is still at its early stage. This development may be impaired by the fact that "classical" 
nonspecific chelators, like edta or tpen, are toxic, and considered inefficient. But we have demonstrated that the tuning of selective N4-tetradentate $\mathrm{Cu}(\mathrm{II})$ chelators led to drugcandidates able to inhibit the ROS production triggered by $\mathrm{Cu}-\mathrm{A} \beta$ and have the capacity to fully reverse the deficit of episodic memory in a reliable non-transgenic mouse model of AD. This clearly confirms that restoration of copper homeostasis is a valuable therapeutic target. The design of metal chelators as therapeutic agents able to counteract deleterious consequences of metal misregulation in $\mathrm{AD}$ brain, must take into account the necessary coordination chemistry background to select the suitable drug-candidates and to enhance the chance of success in clinical trials.

\section{Biographies}

Yan Liu received her PhD degree from Sun Yat-sen University (2007). After post-doctoral positions at Hong-Kong Baptist University (2007-2009, Prof. Zhi-Hong Jiang), and Kyoto University (2010-2013, Prof. Keiji Maruoka), she joined the research group of Bernard Meunier at the Guangdong University of Technology, Guangzhou. Her current research is focused on the development of specific copper-chelators as potential anti-Alzheimer agents.

Michel Nguyen received PhD degree from the University of Toulouse (2001). He worked for six years in medicinal chemistry for Palumed company, where he developed new antibacterial and antimalarial drugs. He is currently Engineer at CNRS-LCC, working on malaria chemotherapy, and on redox metal homeostasis as possible chemotherapy of Alzheimer's disease.

Anne Robert received degrees from the Chemical Engineering School of Toulouse, and University of Toulouse (1985, PhD). She joined the research group of Bernard Meunier at the Laboratoire de Chimie de Coordination du CNRS, in 1985. She is currently Director of Research at the CNRS. Her work is focused on the role of redox metals in biology (biomimetic oxidations, mechanism of action of peroxide based antimalarial drugs), and redox metal homeostasis for chemotherapy of Alzheimer's disease.

Bernard Meunier is Director of Research Emeritus at the CNRS (Toulouse), and Distinguished Professor at the University of Technology of Guangdong in Guangzhou 
(Department of Chemistry) since 2012. He has been an Associate Professor at the "École Polytechnique »(1993-2006) and President of the CNRS (2004-2006). His research covers various fields such as biomimetic oxidations, bioinorganic and medicinal chemistry. Since 2004, he works on the design of copper chelators as potential drug-candidates for the treatment of Alzheimer's disease. Bernard Meunier is co-author of more than 400 publications and 33 patents. He has been elected Member of the French Academy of Sciences in 1999. He was Vice-president (2013-2014) and President (2015-2016). He is Foreign Member of the Polish Academy of Sciences (2005) and Associate Member of the French National Academy of Pharmacy (2013).

\section{Abbreviations}

$\mathrm{AD}$, Alzheimer's disease; A $\beta$, amyloid peptide; APP, Amyloid precursor protein; BBB, blood brain barrier; BDNF, Brain-derived neurotrophic factor; CQ, clioquinol; CRF, Chronic renal failure; DAE, Dialysis-associated encephalopathy; DES, dialysis encephalopathy syndrome; DNA, Deoxyribolucleic acid; edta, Ethylenediaminetetraacetic acid; HD, Hemodialyzed; HO, Heme oxygenase-1; HRP, Horseradish peroxidase; icv, intracerebroventricular; MMP2, Matrix metalloprotease-2; MT, Metallothionein; mZn, “mobile” zinc; NFT, Neurofibrillary tangles; NMDA, $N$-methyl-D-aspartate; ROS, Reduced oxygen species; SOD, Superoxide dismutase; TDMQ, Tetradentate monoquinoline chelator; Tf, Transferrin; tpen, $N, N, N, N$ tetrakis(2-pyridylmethyl)ethylenediamine; Zn-T3, Zinc-transporter-3.

\section{Funding Sources}

This work has been supported by the CNRS since 2003. Palumed provided a strong support for the period 2005-2010. Since 2013, this work is also supported by the NSFC (grant 21502023), the Guangdong Province (Program for Innovative Research Teams and Leading Talents Introduction, grant 2050205) and the University of Technology of the Guangdong (GDUT) (grant 220418037) of the P. R. China.

\section{Acknowledgments}


Authors gratefully acknowledge all colleagues, post-doctoral fellows, $\mathrm{PhD}$ and master students who are or have been involved in the research of specific metal regulators as potential AD drugs.

\section{References}

1. World Alzheimer Report 2015. The global impact of dementia - An Analysis of prevalence, incidence, cost and trends. https://www.alz.co.uk/research/WorldAlzheimerReport2015.pdf; Accessed April 8, 2019 .

2. Bali, J.; Gheinani, A. H.; Zurbriggen, S.; Rajendran, L. Role of genes linked to sporadic Alzheimer's disease risk in the production of -amyloid peptides. PNAS 2012, 109, 15307-15311.

3. Cummings, J. L.; Travis, M.; Zhong, K. Alzheimer's disease drug-development pipeline: few candidates, frequent failures. Alzheimer's Res. Ther. 2014, 6, 37-43.

4. Editorial. Why are drug trials in Alzheimer's disease failing? Lancet 2010, 376, 658; DOI: <url>https://doi.org/10.1016/S0140-6736(10)61316-5.

5. Robert, A.; Benoit-Vical, F.; Liu, Y.; Meunier, B. Small molecules: the past or the future in drug innovation? in Metal ions in life sciences. Sigel, A.; Fresinger, E.; Sigel, R. K. O., Eds. Walter de Gruyter, Berlin, 2019, 19, 17-48.

6. Luczkowski, M. "No screams and cries will convince us that white is white and black is black", an ode to the defenders of amyloid cascade hypothesis of Alzheimer's disease. Coord. Chem. Rev. 2016, 327-328, 35-42.

7. Kepp, K. P. Alzheimer's disease: How metal ions define $\beta$-amyloid function. Coord. Chem. Rev. 2017, 351, 127-159.

8. Lovell, M. A.; Robertson, J. D.; Teesdale, W. J.; Campbell, J. L.; Markesbery, W. R. Copper, iron and zinc in Alzheimer's disease senile plaques. J. Neurol. Sci. 1998, 158, 47-52.

9. Guilloreau, L.; Combalbert, S.; Sournia-Saquet, A.; Mazarguil, H.; Faller, P. Redox chemistry of copper-amyloid-beta: the generation of hydroxyl radical in the presence of ascorbate is linked to redox-potentials and aggregation state. ChemBioChem 2007, 8, $1317-1325$. 
10. Lee, S. J. C.; Nam, E.; Lee, H. J.; Savelieff, M. G.; Lim. M. H. Towards an understanding of amyloid-beta oligomers: characterization, toxicity mechanisms, and inhibitors. Chem. Soc. Rev. 2017, 46, 310-323.

11. Robert, A.; Liu, Y.; Nguyen, M.; Meunier, B. Regulation of copper and iron homeostasis by metal chelators: A possible chemotherapy for Alzheimer's disease. Acc. Chem. Res. 2015, 48, 1332-1339.

12. Barnham, K. J.; Bush, A. I. Biological metals and metal-targeting compounds in major neurodegenerative diseases. Chem. Soc. Rev. 2014, 43, 6727-6749.

13. Perez, L. R.; Franz, K. J. Minding metals: Tailoring multifunctional chelating agents for neurodegenerative disease. Dalton Trans. 2010, 39, 2177-2187.

14. Drüeke, T. B. Intestinal absorption of aluminium in renal failure. Nephrol. Dial. Transplant. 2002, 17, 13-16.

15. Klatzo, I.; Wisniewski, H.; Streicher, E. Experimental production of neurofibrillary degeneration. J. Neuropathol. Exp. Neurol. 1965, 24, 187-199.

16. Corrigan, F. M.; Reynolds, G. P.; Ward, N. I. Hippocampal tin, aluminium and zinc in Alzheimer's disease. BioMetals 1993, 6, 149-154.

17. Schupf, N.; Silverman, W.; Zigman, W. B.; Moretz, R. C.; Wisniewski, H. M. Aluminum and Alzheimers-disease. Lancet 1989, 333, 267-267.

18. McDermott, J. R.; Smith, A. I.; Ikbal, K.; Wisniewski, H. M. Brain aluminum in aging and Alzheimer disease. Neurology 1979, 29, 809-814.

19. Munoz, D. G. Is exposure to aluminum a risk factor for the development of Alzheimer's disease?-No. Arch. Neurol. 1998, 55, 737-739.

20. Schreeder, M. T.; Favero, M. S.; Hughes, J. R.; Petersen, N. J.; Bennett, P. H.; Maynard, J. E. Dialysis encephalopathy and aluminium exposure: an epidemiologic analysis. $J$. Chron. Dis. 1983, 36, 581-593.

21. Russo, L. S.; Beale, G.; Sandroni, S.; Ballinger, W. E. Aluminium intoxication in undialyzed adults with chronic renal failure. J. Neurol. Neurosurg. Psychiatry 1992, 55, 697-700.

22. Rob, P. M.; Niederstadt, C.; Reusche, E. Dementia in patients undergoing long-term dialysis: aetiology, differential diagnoses, epidemiology and management. CNS Drugs 2001, 15, 691-699. 
23. Reusche, E.; Koch, V.; Lindner, B.; Harrison, A. P.; Friedrich, H. J. Alzheimer morphology is not increased in dialysis-associated encephalopathy and long-term hemodialysis. Acta Neuropathol. 2001, 101, 211-216.

24. Cannata-Andía, J. B.; Martin, K. J. The challenge of controlling phosphorus in chronic kidney disease. Nephol. Dial. Transplant. 2016, 31, 541-547.

25. Walton, J. R. Aluminium's involvement in the progression of Alzheimer's disease. $J$. Alz. Dis. 2013, 35, 7-43.

26. Exley, C.; House, E. R. Aluminium in the human brain. Monasch. Chem. 2011, 142, 357-363.

27. Lidski, T. I. Is the Aluminum Hypothesis Dead? J. Occup. Environ. Med. 2014, 56, S73-S77.

28. Van Landeghem, G. F.; D’Haese, P. C.; Lamberts, L. V.; De Broe, M. E. Competition of iron and aluminum for transferrin: the molecular basis for aluminum deposition in iron-overloaded dialysis patients? Exp. Nephrol. 1997, 5, 239-245.

29. Roskams, A. J.; Connor, J. R. Aluminum access to the brain: A role for transferrin and its receptor. Proc. Natl. Acad. Sci. USA 1990, 87, 9024-9027.

30. Aluminum in drinking water. Background document for development of WHO Guidelines for Drinking-water Quality. World Health Organization, Geneva, 2010. Available with $\quad$ https://www.who.int/water_sanitation_health/waterquality/guidelines/chemicals/aluminium.pdf?ua $=1$

31. Andreini, C.; Banci, L.; Bertini, I.; Rosato, A. Counting the zinc-proteins encoded in the human genome. J. Proteome Res. 2006, 5, 196-201.

32. Portbury, S. D.; Adlard, P. A. Zinc signal in brain diseases. Int. J. Mol. Sci. 2017, 18, 2506.

33. Shetty, M. S.; Sharma, M.; Sajikumar, S. Chelation of hippocampal zinc enhances longterm potentiation and synaptic tagging/capture in CA1 pyramidal neurons of aged rats: Implications to aging ang memory. Aging Cell 2017, 16, 136-148 and references cited.

34. Sensi, S. L.; Paoletti, P.; Koh, J-Y.; Aizenman, E.; Bush, A. I.; Hershfinkel, M. The neurophysiology and pathology of brain zinc. J Neurosci. 2011, 31, 16076-16085.

35. Vašák, M.; Meloni, G. Mammalian metallothionein-3: New functional and structural insights. Int. J. Mol. Sci. 2017, 18, 1117. 
36. Huang, E. P. Metals ions and synaptic transmission: Think zinc. Proc. Natl. Acad. Sci. USA 1997, 94, 13386-13387.

37. Jalali-Yazdi, F.; Chowdhury, S.; Yoshioka, C.; Gouaux, E. Mechanisms for zinc and proton inhibition of the GluN1/GluN2A NMDA receptor. Cell 2018, 175, 1520-1532.

38. Radford, R. J.; Lippard, S. J. Chelators for investigating metalloneurochemistry. Curr. Opin. Chem. Biol. 2013, 17, 129-136.

39. Smidt, K.; Rungby, J. ZnT3: a zinc transporter active in several organs. Biometals 2012, $25,1-8$.

40. Danscher, G.; Jensen, K. B.; Frederickson, C. J.; Kemp, K.; Andreasen, A.; Juhl, S.; Stoltenberg, S.; Ravid, R. Increased amount of zinc in the hippocampus and amygdala of Alzheimer's diseased brains: A proton-induced X-ray emission spectroscopic analysis of cryostat sections from autopsy material. J. Neurosci. Meth. 1997, 76, 53-59.

41. Talmard, C.; Bouzan, A.; Faller, P. Zinc binding to amyloid- $\beta$ : Isothermal titration calorimetry and Zn competition experiments with Zn sensors. Biochemistry 2007, 46, 13658-13666.

42. Crouch, P. J.; Tew, D. J.; Du, T.; Nguyen, D. N.; Caragounis, A.; Filiz, G.; Blake, R. E.; Trounce, I. A.; Soon, C. P. W.; Laughton, K.; Perez, K. A.; Li, Q.-X.; Cherny, R. A.; Masters, C. L.; Barnham, K. J.; White, A. R. Restored degradation of the Alzheimer's amyloid- $\beta$ peptide by targeting amyloid formation. J. Neurochem. 2009, 108, 11981207.

43. Huang, Y.; Wu, Z.; Cao, Y.; Lang, M.; Lu, B.; Zhou, B. Zinc Binding Directly Regulates Tau Toxicity Independent of Tau Hyperphosphorylation. Cell Rep. 2014, 8, $831-842$.

44. Sun, X.-Y.; Wei, Y.-P.; Xiong, Y.; Wang, X.-C.; Xie, A.-J.; Wang, X.-L.; Yang, Y.; Wang, Q.; Lu, Y.-M.; Liu, R.; Wang, J.-Z. Synaptic Released Zinc Promotes Tau Hyperphosphorylation by Inhibition of Protein Phosphatase 2A (PP2A). J. Biol. Chem. 2012, 287, 11174-11182, 
45. Aliès, B.; Sasaki, I.; Proux, O.; Sayen, S.; Guillon, E.; Faller, P.; Hureau, C. Zn impact $\mathrm{Cu}$ coordination to amyloid- $\beta$, the Alzheimer's peptide, but not the ROS production and the associated cell toxicity. Chem. Commun. 2013, 49, 1214-1216.

46. Wong, B. X.; Tsatsanis, A.; Lim, L. Q.; Adlard, P. A.; Bush, A. I.; Duce, J. A. $\beta$ Amyloid precursor protein does not possess ferroxidase activity but does stabilize the cell surface ferrous iron exporter ferroportin. PLoS One 2014, 9, e114174.

47. J. Worm-Petersen. Vitamin B12 haemoglobin and iron concentration in human brain tissue. Acta Neurol. Scand. 1964, 40, 241-248.

48. Kalpouzos, G.; Garzon, B.; Stinikov, R.; Heiland C.; Salami, A.; Persson, J.; Bäckman, L. Higher striatal iron concentration is linked to frontostriatal underactivation and poorer memory in normal aging. Cerebral Cortex, 2017, 27, 3427-3436.

49. Goodman, L. Alzheimer's disease; a clinico-pathologic analysis of twenty-three cases with a theory on pathogenesis. J. Nerv. Ment. Dis. 1953, 118, 97-130.

50. Scott, L. E.; Orvig, C. Medicinal inorganic chemistry approaches to passivation and removal of aberrant metal ions in disease Chem. Rev. 2009, 109, 4885-4910.

51. Bousejra El-Garah, F.; Bijani, C.; Coppel, Y.; Faller, P.; Hureau, C. Iron(II) binding to amyloid- $\beta$, the Alzheimer's peptide. Inorg. Chem. 2011, 50, 9024-9030.

52. Miura, T.; Suzuki, K.; Takeuchi, H. Binding of iron(III) to the single tyrosine residue of amyloid $\beta$-peptide probed by Raman spectroscopy. J. Mol. Struct. 2001, 598, 79-84.

53. Nguyen, M.; Huang, M.; Liu, Y.; Meunier, B. Is iron associated with amyloid involved in the oxidative stress of Alzheimer's disease ? C. R. Chimie, 2017, 20, 987-989.

54. Kirschvink, J. L.; Kobayashi-Kirschvink, A.; Woodford, B. J. Magnetite biomineralization in the human brain. Proc. Natl. Acad. Sci. USA 1992, 89, 7683-7687.

55. Gao, L.; Zhuang, J.; Nie, L.; Zhang, J.; Zhang, Y.; Gu, N.; Wang, T.; Feng, J.; Yang, D.; Perrett, S.; Yan, X. Intrinsic peroxidase-like activity of ferromagnetic nanoparticles Nat. Nanotechnol. 2007, 2, 577-583.

56. Teller, S.; Tahirbegi, I. B.; Mir, M.; Samitier, J.; Soriano, J. Magnetite-Amyloid- $\beta$ deteriorates activity and functional organization in an in vitro model for Alzheimer's disease. Sci. Rep. 2015, 5, 17261.

57. Maher, B.; Ahmed, I. A. M.; Karloukovski, V.; MacLaren, D. A.; Foulds, P. G.; Allsop, D.; Mann, D. M. A.; Torres-Jardón, R.; Calderon-Garciduenas, L. Magnetite pollution 
nanoparticles in the human brain. Proc. Natl. Acad. Sci. USA 2016, 113, 10797-10801.

58. Gumpelmayer, M.; Nguyen, M.; Molnár, G.; Bousseksou, A.; Meunier, B.; Robert, A. Magnetite $\mathrm{Fe}_{3} \mathrm{O}_{4}$ has no intrinsic peroxidase activity, and is probably not involved in Alzheimer's oxidative stress. Angew. Chem. Int. Ed. 2018, 57, 14758-14763.

59. Shabir, O.; Berwick, J.; Francis, S. E. Neurovascular dysfunction in vascular dementia, Alzheimer's and atherosclerosis. Br. Med. J. Neurosci. 2018, 19, 62.

60. Cullen, K. M.; Kócsi, Z.; Stone, J. Microvascular pathology in the aging human brain: evidence that senile plaques are sites of microhaemorrhages. Neurobiol. Aging 2006, 27, 1786 .

61. Yuan, C.; Gao, Z. A $\beta$ interacts with both the iron center and the porphyrin ring of heme: Mechanism of heme's action on $\mathrm{A} \beta$ aggregation and disaggregation. Chem. Res. Toxicol. 2013, 26, 262-269.

62. Pramanik, D.; Ghosh, C.; Ghosh Dey, S. Heme-Cu bound A $\beta$ peptides: spectroscopic characterization, reactivity, and relevance to Alzheimer's disease. J. Am. Chem. Soc. 2011, 133, 15545-15552.

63. Barone, E.; Di Domenico, F.; Mancuso, C.; Butterfield, D. A. The Janus face of the heme oxygenase/biliverdin reductase system in Alzheimer disease: it's time for reconciliation. Neurobiol. Dis. 2014, 62, 144-159.

64. Wang, J.; Doré, S. Heme oxygenase-1 exacerbates early brain injury after intracerebral haemorrhage. Brain 2007, 130, 1643-1652.

65. Scheltens, P.; Blennow, K.; Breteler, M. M. B.; de Strooper, B.; Frisoni, G. B.; Salloway, S.; Van der Flier, W. M. Alzheimer's disease. Lancet 2016, 388, 505-517.

66. Gaier, E. D.; Eipper, B. A.; Mains, R. E. Copper signaling in the mammalian nervous system: Synaptic effects. J. Neurosci. Res. 2013, 91, 2-19.

67. Rios, M.; Habecker, B.; Sasaoka, T.; Eisenhofer, G.; Tian, H.; Landis, S.; Chikaraishi, D.; Roffler-Tarlov, S. Catecholamine synthesis is mediated by tyrosinase in the absence of tyrosine hydroxylase. J. Neurosci. 1999, 19, 3519-3526.

68. Xiao, T.; Ackerman, C. M.; Carroll, E. C.; Jia, S.; Hoagland, A.; Chan, J.; Thai, B.; Liu, C. S.; Isacoff, E. Y.; Chang, C. J. Copper regulates rest-activity cycles through the locus coeruleus-norepinephrine system. Nat. Chem. Biol. 2018, 14, 655-663. 
69. Bayer, T. A.; Schäfer, S.; Simons, A.; Kemmling, A.; Kamer, T.; Tepest, R.; Eckert, A.; Schüssel, K.; Eikenberg, O.; Sturchler-Pierrat, C.; Abramowski, D.; Staufenbiel, M.; Multhaup, G. Dietary Cu stabilizes brain superoxide dismutase 1 activity and reduces A $\beta$ production in APP23 transgenic mice. Proc. Natl. Acad. Sci. USA 2003, 100, 1418714192.

70. Rowinska-Zyrek, M.; Salerno, M.; Kozlowski, H. Neurodegenerative diseases Understanding their molecular bases and the progress in the development of potential treatments. Coord. Chem. Rev. 2015, 284, 298-312.

71. Cherny, R. A.; Atwood, C. S.; Xilinas, M. E.; Gray, D. N.; Jones, W. D.; McLean, C. A.; Barnham, K. J.; Volitakis, I.; Fraser, F. W.; Kim, Y.-S.; Huang, X.; Goldstein, L. E.; Moir, R. D.; Lim, J. T.; Beyreuther, K.; Zheng, H.; Tanzi, R. E.; Masters, C. L.; Bush, A. I. Treatment with a copper-zinc chelator markedly and rapidly inhibits beta-amyloid accumulation in Alzheimer's disease transgenic mice. Neuron 2001, 30, 665-676.

72. Andersson, D. A.; Gentry, C.; Moss, S.; Bevan, S. Clioquinol and pyrithione activate TRPA1 by increasing intracellular $\mathrm{Zn}^{2+}$. Proc. Natl. Acad. Sci. USA 2009, 109, 83748379 .

73. https://www.prnewswire.com/news-releases/prana-biotechnology-announcespreliminary-results-of-phase-2-imagine-trial-of-pbt2-in-alzheimers-disease253173581.html. Press release dated March 31, 2014. Accessed April 8th, 2019.

74. Nguyen, M. ; Robert, A.; Sournia-Saquet, A.; Vendier, L.; Meunier, B. The necessity of having a tetradentate ligand to extract copper(II) ions from amyloids. ChemistryOpen 2015, 4, 27-31.

75. Nguyen, M.; Vendier, L. ; Stigliani, J.-L. ; Meunier, B. ; Robert, A. Structures of copper and zinc complexes of PBT2, a chelating agent evaluated as potential drug for neurodegenerative diseases. Eur. J. Inorg. Chem. 2017, 600-608.

76. a) Deraeve, C.; Boldron, C. ; Maraval, A.; Mazarguil, H.; Gornitzka, H.; Vendier, L.; Pitié, M.; Meunier, B. Preparation and study of new poly-8-hydroxyquinoline chelators for an anti-Alzheimer strategy. Chem. Eur. J. 2008, 14, 682-696. b) Deraeve, C.; Pitié, M.; Mazarguil, H.; Meunier, B. Bis-8-hydroxyquinoline ligands as potential antiAlzheimer agents. New J. Chem. 2007, 31, 193-195.

77. Nguyen, M.; Robert, A.; Sournia-Saquet, A.; Vendier, L.; Meunier, B. Characterization 
of new specific copper chelators as potential drugs for the treatment of Alzheimer's disease. Chem. Eur. J. 2014, 20, 6771-6785.

78. Nguyen, M.; Bijani, C.; Martins, N.; Meunier, B.; Robert, A. Transfer of copper from an amyloid to a natural copper-carrier peptide with a specific mediating ligand. Chem. Eur. J. 2015, 21, 17085-17090.

79. Liu, Y.; Liu, X.; Huang, D.; Huang, M.; Wang, D.; Nguyen, M.; Robert, A.; Meunier, B. Chinese patent 201610369550.X, May 27, 2016. WO 2017/202360 A1.

80. Zhang, W.; Huang, D.; Huang, M.; Huang, J.; Wang, D.; Liu, X.; Nguyen, M.; Vendier, L.; Mazères, S.; Robert, A.; Liu, Y.; Meunier, B. Preparation of new tetradentate copper chelators as potential anti-Alzheimer agents. ChemMedChem. 2018, 13, 684-704.

81. Hansch, C. ; Leo, A. J. Substituent constant for correlation analysis in chemistry and biology, New York: Wiley (1979).

82. Zhang, W.; Liu, Y.; Hureau, C.; Robert, A.; Meunier, B. N4-Tetradentate chelators efficiently regulate copper homeostasis and prevent ROS production induced by copperamyloid- $\beta_{1-16}$, even in the presence of an excess of zinc. Chem. Eur. J. 2018, 24, 78257829.

83. The cell unit contained two Cu-TDMQ20 complexes. In both of them, the copper ion was pentacoordinated in a square-based pyramid. The nearly perfect base plane consisted of the $4 \mathrm{~N}$ of the TDMQ ligand. The axial ligand was either $\mathrm{Cl}^{-}[\mathrm{d}(\mathrm{Cu}-\mathrm{Cl})=$ $2.59 \AA]$ or $\mathrm{H}_{2} \mathrm{O}[\mathrm{d}(\mathrm{Cu}-\mathrm{Cl})=2.38 \AA]$. In addition, three unbound $\mathrm{Cl}-$ and two $\mathrm{H}_{2} \mathrm{O}$ were detected in the cell. Figure $4 \mathrm{a}$ is the ortep drawing of only one molecule present in the unit cell. Crystallographic data for the structure of $\mathrm{Cu}(\mathrm{II})-\mathrm{TDMQ} 20$ were deposited with the Cambridge Crystallographic Data Centre (CCDC) as supplementary publication no. CCDC 1920739. Copies of the data can be obtained free of charge from the CCDC (12 Union Road, Cambridge CB2 1EZ, UK; e-mail: deposit@ccdc.cam.ac.uk; Web site: http://www.ccdc.cam.ac.uk.

84. Huang, J.; Nguyen, M.; Liu, Y.; Robert, A.; Meunier, B. The TDMQ regulators of copper homeostasis do not disturb $\mathrm{Cu}, \mathrm{Zn}-\mathrm{SOD}$ and tyrosinase activity, nor the $\mathrm{Cu}(\mathrm{III})$ cofactor vitamin B12. Eur. J. Inorg. Chem. 2019, 1384-1388.

85. Boldron, C.; Van der Auwera, I.; Deraeve, C.; Gornitzka, H.; Wera, S.; Pitié, M.; Van Leuven, F.; Meunier, B. Preparation of cyclo-Phen-type ligands: chelators of potential 
therapeutic agents in the treatment of neurodegenerative diseases. ChemBioChem. 2005, 6, 1976-1980.

86. Ceccom, J.; Coslédan, F.; Halley, H.; Francès, B.; Lassalle, J.-M.; Meunier, B. Copper chelator induced efficient episodic memory recovery in a non-transgenic Alzheimer's mouse model. PloS One 2012, 7, 43105. Episodic memory of non-transgenic AD mice treated with PA1637 at $25 \mathrm{mg} / \mathrm{kg}$ by oral route (grey bar), compared to healthy control mice (white bar) and untreated AD mice (black bar). Healthy control mice receiving icv injection of vehicle exhibited basal scores of episodic memory. Comparatively, the icv injection of $A \beta_{1-42}$ resulted in a significant decrease of the memory (black bar, $p=$ 0.008). Treatment by PA1637 significantly improved the memory score of mice having received $A \beta_{42-1}$ (grey bar, $\mathrm{p}=0.003$ ). $\mathrm{P}$ values are given for the Fisher's LSD test. stands for $\mathrm{p}$ values in the range $0.01-0.001$. 